\title{
Association of dry matter intake and energy balance prepartum and postpartum with health disorders postpartum: Part I. Calving disorders and metritis
}

\author{
J. Pérez-Báez, ${ }^{1}$ C. A. Risco, ${ }^{1}$ R. C. Chebel, ${ }^{1}$ G. C. Gomes, ${ }^{1}$ L. F. Greco, ${ }^{2}$ S. Tao, ${ }^{2 *}$ I. M. Thompson, ${ }^{2}$ \\ B. C. do Amaral, ${ }^{2}$ M. G. Zenobi, ${ }^{2}$ N. Martinez, ${ }^{2}$ C. R. Staples, ${ }^{2}$ G. E. Dahl, ${ }^{2}$ J. A. Hernández, ${ }^{1}$ \\ J. E. P. Santos, ${ }^{2,3}$ and K. N. Galvão ${ }^{1,3} \dagger$ \\ ${ }^{1}$ Department of Large Animal Clinical Sciences, University of Florida, Gainesville 32610 \\ ${ }^{2}$ Department of Animal Sciences, University of Florida, Gainesville 32610 \\ ${ }^{3}$ D. H. Barron Reproductive and Perinatal Biology Research Program, University of Florida, Gainesville 32610
}

\section{ABSTRACT}

The main objective of this study was to determine the association of dry matter intake as percentage of body weight (DMI\%BW) and energy balance (EB) prepartum ( $-21 \mathrm{~d}$ relative to parturition) and postpartum (28 d) with calving disorders (CDZ; dystocia, twins, and stillbirths; $\mathrm{n}=101)$ and metritis $(\mathrm{n}=114)$. For this, $\mathrm{DMI} \% \mathrm{BW}$ and $\mathrm{EB}$ were the independent variables and CDZ and metritis were the dependent variables. A secondary objective was to evaluate prepartum $\mathrm{DMI} \% \mathrm{BW}$ and $\mathrm{EB}$ as predictors of $\mathrm{CDZ}$ and metritis. For this, CDZ and metritis were the independent variables and $\mathrm{DMI} \% \mathrm{BW}$ and $\mathrm{EB}$ were the dependent variables. Data from 476 cows from 9 experiments were compiled. Cows that developed CDZ had lesser postpartum DMI\%BW from d 3 to 12 and lesser energycorrected milk (ECM) than cows that did not develop CDZ. Dry matter intake as percentage of BW and EB prepartum did not affect the odds of CDZ. Cows with metritis had lesser prepartum DMI\%BW and EB. Each 0.1-percentage point decrease in the average DMI\%BW and each 1-Mcal decrease in the average EB in the last $3 \mathrm{~d}$ prepartum increased the odds of having metritis by $8 \%$. The average DMI\%BW and EB during the last $3 \mathrm{~d}$ prepartum produced significant cut-offs to predict metritis postpartum, which were $\leq 1.6 \% / \mathrm{d}$ and $\leq 2.5 \mathrm{Mcal} / \mathrm{d}$, respectively. Cows that developed metritis had lesser overall postpartum DMI\%BW and ECM and lesser EB from d 2 to 5 and from d 7 to 11 than cows that did not develop metritis. The main limitation in this study is that the time-order of disease

Received October 18, 2018.

Accepted May 26, 2019.

* Current address: Department of Animal and Dairy Science, University of Georgia, Tifton, GA 31793.

†Corresponding author: galvaok@ufl.edu relative to $\mathrm{DMI} \% \mathrm{BW}$ and $\mathrm{ECM}$ is inconsistent such that postpartum outcomes were measured before and after disease, which was diagnosed at variable intervals after calving. In summary, prepartum DMI\%BW and EB were associated with and were predictors of metritis although the effect sizes were small for metritis, and calving disorders and metritis were associated with decreased DMI\%BW and ECM postpartum.

Key words: dry matter intake, transition period, calving disorder, metritis, dairy cow

\section{INTRODUCTION}

Transition dairy cows experience a decline in DMI in the last week of gestation, and the early-lactation period is typically characterized by an increase in the incidence of disorders that compromise production and survival. The decline in DMI during the prepartum period occurs in the last $10 \mathrm{~d}$ of gestation, although it is more pronounced in the last $4 \mathrm{~d}$ before calving (Hayirli et al., 2002). The decrease in DMI prepartum and insufficient DMI postpartum lead to a state of negative nutrient balance characterized by lipid mobilization and an increase in circulating concentrations of nonesterified fatty acids (NEFA) and BHB (Drackley, 1999; Grummer et al., 2004; French, 2006). Concentrations of NEFA $\geq 0.3 \mathrm{~m} M$ within 2 wk prepartum have been shown to increase the risk of uterine disorders such as metritis (Ospina et al., 2010b; Sepúlveda-Varas et al., 2015). Metritis is associated with reduced milk yield, impaired reproductive performance, and increased culling, which taken together result in economic losses (Overton and Fetrow, 2008; Mahnani et al., 2015). Cows with calving disorders (CDZ) such as dystocia, twins, or stillbirths, which are major risk factors for metritis, also have increased risk of culling (Vergara et al., 2014). Therefore, given the relevance of CDZ and uterine disorders, it is important to understand the 


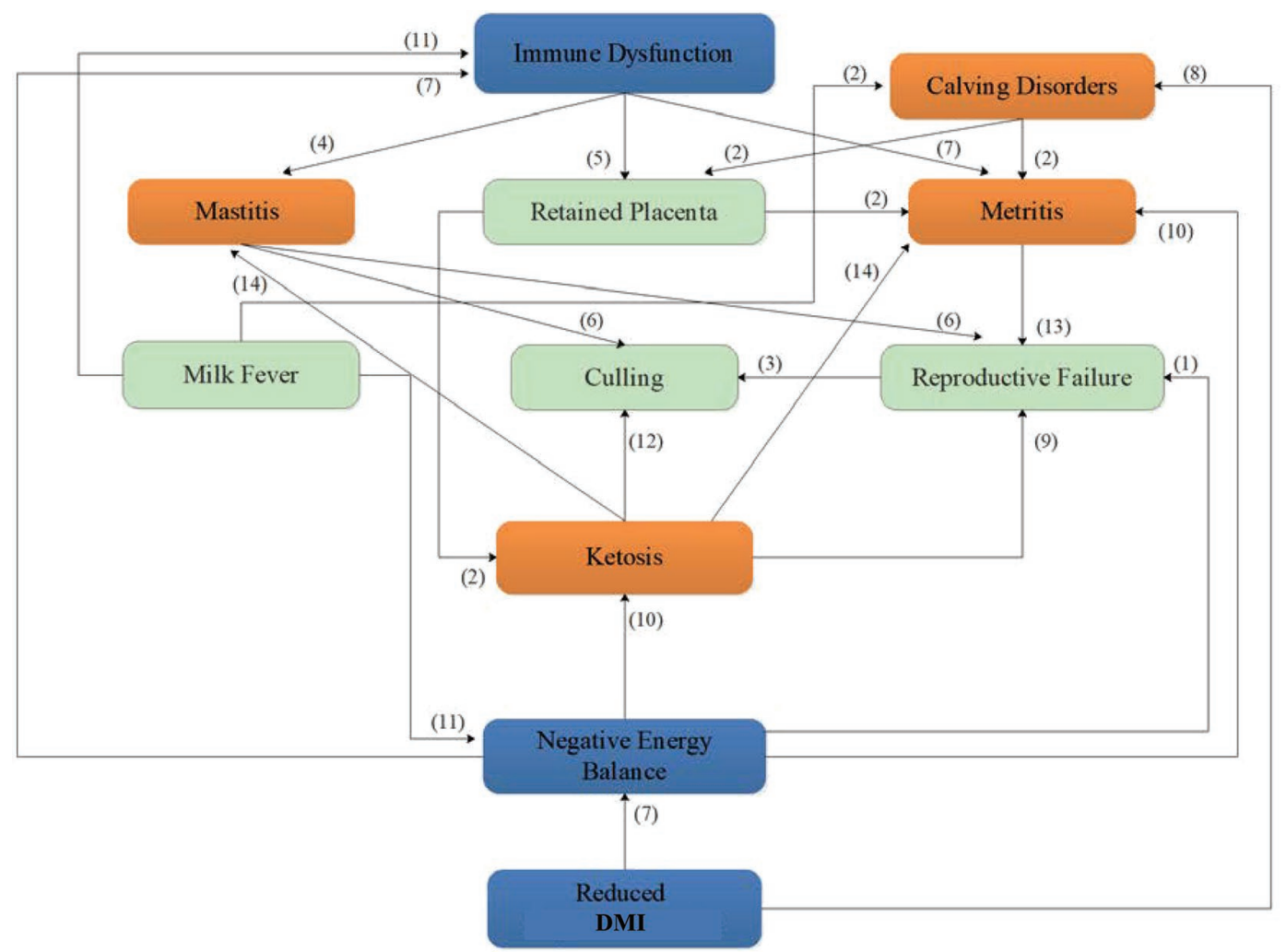

Figure 1. Causal diagram showing the relationship of DMI and energy balance with postpartum diseases and its consequences. Based on the work of the following: 1 = Beam and Butler (1999); 2 = Correa et al. (1993); 3 = Gröhn et al. (1998); $4=$ Suriyasathaporn et al. (2000); 5 $=$ Kimura et al. (2002); $6=$ Santos et al. (2004); $7=$ Hammon et al. (2006); $8=$ Proudfoot et al. (2009); $9=$ Ospina et al. (2010a); 10 = Ospina et al. (2010b); $11=$ Martinez et al. (2012); $12=$ McArt et al. (2012); $13=$ Ribeiro et al. (2013); $14=$ Raboisson et al. (2014).

factors associated with increased risk of these disorders to be able to devise strategies to reduce their incidence and mitigate their negative effects on reproductive performance, culling, and profitability.

Previous research has observed that cows with severe metritis had reduced prepartum DMI, more noticeably in the last week of gestation, compared with cows with no metritis (Huzzey et al., 2007). Furthermore, each 1-kg decrease in DMI in the last week of gestation increased the odds of severe metritis by 2.9 times (Huzzey et al., 2007). Nonetheless, because cows with other disorders (e.g., mastitis, vaginal tears, digestive disorder) were excluded, these estimates are from a subset of the population and may not represent the whole population. In addition, the contribution of DMI to a predictive model that includes other risk factors for metritis such as parity, CDZ, and retained placenta (RP) has not been evaluated. Therefore, further evaluation of prepartum DMI as a risk factor for metritis is warranted. Although a few studies have evaluated the association of DMI with dystocia (Proudfoot et al., 2009) and metritis (Huzzey et al., 2007; Schirmann et al., 2016), a comprehensive study of the association of pre- and postpartum DMI as percentage of BW (DMI\%BW) and pre- and postpartum energy balance (EB) with CDZ and metritis is lacking.

The hypothesis of this study was that reductions in $\mathrm{DMI} \% \mathrm{BW}$ and EB during the transition period are associated with CDZ and metritis (Figure 1). Our main objective was to evaluate the association of prepartum and postpartum DMI\%BW and EB with CDZ (dystocia, twins, and stillbirths) and metritis. A secondary objective was to evaluate the use of prepartum $\mathrm{DMI} \% \mathrm{BW}$ and EB as predictors of CDZ and metritis.

\section{MATERIALS AND METHODS}

\section{Experimental Design and Sample Size}

A retrospective longitudinal study was performed using the data from 476 cows (139 primigravid and 337 multigravid) from 9 experiments conducted at the University of Florida research dairy unit, located in the city of Hague, Florida. This was a convenience sample; 
Table 1. Frequency of calving and uterine disorders diagnosed during the first $21 \mathrm{~d}$ postpartum

\begin{tabular}{lcccc}
\hline Disease/disorder & Frequency & Percentage, $\%$ & MPP $^{1}$ & IQR $^{2}$ \\
\hline Calving problems & & & & 0 \\
Dystocia & 101 & 21.2 & 0 & 0 \\
Calving score 5 & 79 & 16.6 & 0 & 0 \\
Calving score 4 & 4 & 0.8 & 0 & 0 \\
Calving score 3 & 13 & 2.7 & 0 & 0 \\
Calving score 2 & 35 & 7.4 & 0 & 0 \\
Calving score 1 & 27 & 5.7 & 0 & 0 \\
Twins & 397 & 83.4 & 0 & 0 \\
Stillbirth & 13 & 2.7 & 0 & 3 \\
Metritis & 25 & 5.3 & 0 & $5(2-12)$ \\
\hline
\end{tabular}

${ }^{1}$ Average days postpartum when the disorder was diagnosed (minimum-maximum in parentheses).

${ }^{2}$ Interquartile range.

${ }^{3}$ Calving problems $=$ twins, stillbirth, and dystocia (cows with calving ease score $\geq 2$ were considered to have dystocia). Calving score: 1 = no assistance; 2 = assistance by 1 person without the use of mechanical traction; $3=$ assistance by 2 or more people; $4=$ assistance with mechanical traction; $5=$ fetotomy or cesarean section. Sixteen cows with calving problems had more than 1 condition.

therefore, no a priori sample size calculation was performed. For continuous variables, approximately 100 cows in the affected group $(\mathrm{CDZ}, \mathrm{n}=101$; metritis, $\mathrm{n}$ $=114$; Table 1 ) would be needed to detect significant differences with an effect size of 0.20 (e.g., difference in DMI of $0.1 \% / d$ when prepartum $\mathrm{SD}$ is $0.5 \% / \mathrm{d}$ of $\mathrm{DMI} \% \mathrm{BW}), \alpha$ of 0.05 , and $\beta$ of 0.2 . Individual experiments were approved by the University of Florida Animal Research Committee.

The University of Florida dairy unit milked approximately 500 Holstein cows twice daily, with a rolling herd average of approximately $10,500 \mathrm{~kg} / \mathrm{cow}$ and an average BW of $560 \mathrm{~kg}$ (range: $371-793 \mathrm{~kg}$ ) for primigravid cows and $660 \mathrm{~kg}$ (range: $459-898 \mathrm{~kg}$ ) for multigravid cows. The freestall beds and walking alleys were cleaned twice daily. Clean and dry sand was added on the top of the freestall beds twice weekly. Fans with misters and sprinklers over the feed rail were present in the barns and activated when environmental temperatures increased above $20^{\circ} \mathrm{C}$. There were 2 pre- and postpartum pens, each with a maximum capacity of 30 cows. The stocking density was maintained between 80 and $100 \%$. Cows were vaccinated and treated for common diseases or disorders according to the standard operating procedures developed with participation of the veterinarians from University of Florida College of Veterinary Medicine Food Animal Reproduction and Medicine Service (FARMS).

The experiments were conducted from 2007 to 2015 . Six of the 9 experiments were conducted during the hot months (June to October) to evaluate the effect of evaporative cooling during the dry period on production measures (do Amaral et al., 2009, 2011; Tao et al., 2011, 2012; Gomes, 2014; Thompson et al., 2014). For these experiments, cows were provided with shade only or with shade plus evaporative cooling with fans and sprinklers. The average environmental temperature during the $3 \mathrm{wk}$ before calving for these experiments was $26.9 \pm 2.0^{\circ} \mathrm{C}$, and the temperature-humidity index (THI) was $77.7 \pm 2.8$. Herein, we maintained the categorization of heat stress abatement applied in these 6 previous experiments, resulting in cows categorized as hot with evaporative cooling $(\mathrm{n}=108)$ or hot without evaporative cooling $(\mathrm{n}=106)$. In the remaining studies, prepartum cows were enrolled from December to May with an average environmental temperature of $16.6 \pm 3.4^{\circ} \mathrm{C}$ and THI of $61.8 \pm 8.9$ (Greco, 2014; Martinez et al., 2018; Zenobi et al., 2018), and cows were provided with evaporative cooling with fans and sprinklers when temperatures increased above $20^{\circ} \mathrm{C}$. Fans and sprinklers turned on and off automatically based on thermostat reading. Fans stayed on while environmental temperature exceeded $20^{\circ} \mathrm{C}$, but sprinklers were on cycles of $1 \mathrm{~min}$ on and $3 \mathrm{~min}$ off. Cows enrolled in the experiments from December to May could still be exposed heat stress. As far as we know, a heat stress THI cut-off for the dry period has not been established; therefore, we chose a prepartum cut-off of THI $\geq 70$ as the midpoint between the traditional (72) and revised (68) THI cut-offs for lactating dairy cows (Armstrong, 1994; Zimbelman et al., 2009). Hence, we categorized cows as hot with evaporative cooling when the average THI during the last 3 wk prepartum was $\geq 70$ ( $\mathrm{n}=$ 58 cows) and cool when the average THI for the last 3 wk prepartum was $<70(\mathrm{n}=204)$. To account for any conditional effect of heat abatement, the variable heat stress abatement was created: cool, hot without evaporative cooling, and hot with evaporative cooling. The following formula was used to calculate the THI according to Dikmen and Hansen (2009): 


$$
\begin{gathered}
\text { THI }=0.8^{\circ} \text { ambient temperature } \\
+[(\text { relative humidity } / 100) \\
\times(\text { ambient temperature }-14.3)]+46.4 .
\end{gathered}
$$

The meteorological data obtained from Weather Underground (2016) for the city of Hague, Florida, was used to calculate THI.

\section{Measurement of DMI}

Cow DMI was recorded daily using a system with individual feeding gates (Calan gates, American Calan Inc., Northwood, NH). For this study, we used DMI collected from d -21 to -1 prepartum and from d 1 to 28 postpartum. Dry matter intake on the day of calving (d 0) was not included because upon parturition the diet changed from a prepartum diet to a lactating diet and intake could not be accurately recorded.

\section{Milk Yield and ECM}

Cows were milked twice a day, and milk production was recorded automatically using milk meters (AfiFlo; S.A.E. Afikim, Kibbutz Afikim, Israel). Data for milk components such as concentrations of fat, true protein, and lactose were available either daily $(\mathrm{n}=356)$ or weekly $(\mathrm{n}=120)$. For cows sampled weekly, daily measurements were estimated by interpolation. Milk fat percentage decreased linearly from wk 1 to 4 of lactation (Gross et al., 2011); therefore, interpolation would be an acceptable method for estimating daily fat percentage. For example, when fat percentage was available for d 7 (fat $\%=3.12$ ) and d 14 (fat $\%=$ 3.55) postpartum, fat percentage on each subsequent day from $\mathrm{d} 7$ to 14 was calculated using the following formula:

fat $\%$ subsequent day $=$

$[($ fat $\%$ d $14-$ fat $\%$ d 7$) / 7]+$ fat $\%$ previous day.

For d 8, fat $\%$ d $8=[(3.55-3.12) / 7]+$ fat $\%$ d $7=$ $0.06+3.12=3.18 \%$. Energy-corrected milk was calculated as follows (derived from NRC, 2001):

$$
\begin{gathered}
\mathrm{ECM}=(0.3246 \times \mathrm{kg} \text { of milk })+(12.86 \times \mathrm{kg} \text { of fat }) \\
+(7.04 \times \mathrm{kg} \text { of protein })
\end{gathered}
$$

\section{$B W$ and BCS}

Cows were weighed daily ( $\mathrm{n}=232$ cows) or weekly $(\mathrm{n}=230$ cows) using a digital scale (AfiWeight, S.A.E.
Afikim). For cows weighed weekly, daily BW was estimated by interpolation. The prepartum BW was not available for 14 cows. Body weight was used to calculate DMI\%BW and EB. Body condition was scored weekly by a member of the research team in each experiment prepartum (range: $\mathrm{d}-21$ to -1 relative to parturition) and postpartum (range: d 0 to 28 relative to parturition) using a 1-to-5 scale ( $1=$ emaciated, $5=$ obese $)$ according to Ferguson et al. (1994). Agreement among BCS observers was not evaluated.

\section{$E B$}

Prepartum and postpartum EB were calculated using NRC (2001) equations for energy requirements as follows:

$$
\begin{gathered}
\mathrm{EB} \text { prepartum }=\mathrm{NE}_{\mathrm{L}} \text { intake } \\
-\left(\mathrm{NE}_{\mathrm{L}} \text { pregnancy }+\mathrm{NE}_{\mathrm{L}} \text { maintenance }\right), \\
\mathrm{EB} \text { postpartum }=\mathrm{NE}_{\mathrm{L}} \text { intake } \\
-\left(\mathrm{NE}_{\mathrm{L}} \text { maintenance }+\mathrm{NE}_{\mathrm{L}} \text { milk }\right),
\end{gathered}
$$

where $\mathrm{NE}_{\mathrm{L}}$ intake, $\mathrm{NE}_{\mathrm{L}}$ maintenance, $\mathrm{NE}_{\mathrm{L}}$ pregnancy, and $\mathrm{NE}_{\mathrm{L}}$ milk were calculated as follows:

$$
\begin{aligned}
& \mathrm{NE}_{\mathrm{L}} \text { intake }=\mathrm{DMI} \times \mathrm{NE}_{\mathrm{L}} \text { of the diet, } \\
& \mathrm{NE}_{\mathrm{L}} \text { maintenance }=\left(\mathrm{BW}^{0.75} \times 0.08\right),
\end{aligned}
$$

$\mathrm{NE}_{\mathrm{L}}$ pregnancy $=[(0.00318 \times$ day of gestation

$$
-0.0352) \times(\text { calf } \mathrm{BW} / 45)] / 0.218
$$

$\mathrm{NE}_{\mathrm{L}}$ milk $=(9.35 \times$ milk yield $\times$ fat $\% / 100)$

$+(5.35 \times$ milk yield $\times$ protein $\% / 100)$

$+(3.95 \times$ milk yield $\times$ lactose $\% / 100)$.

\section{Health Disorders}

Detailed paper and electronic health records were kept for each cow. Each cow underwent a complete physical examination before enrollment in the initial trials, and cows showing signs of disease or disorders such as mastitis, lameness, digestive disorders, or pneumonia were not enrolled in the trials. Each cow underwent scheduled complete physical examinations by a trained herdsperson or by a veterinarian from FARMS at University of Florida on d 4, 7, and 12 postpartum. Furthermore, cow attitude was monitored daily prepartum by a member of the research team when cows were 
individually fed at 0600 and $1800 \mathrm{~h}$ and throughout the day when feed was pushed manually using a shovel every $2 \mathrm{~h}$ from 0800 to $2000 \mathrm{~h}$. Any cow showing signs of depression, inappetence, lethargy, altered stride, or inflammation of the mammary gland underwent a physical examination by a trained herdsperson or by a FARMS veterinarian. Cows that became sick during the prepartum period were excluded. In addition to cow attitude, daily milk yield was monitored postpartum. Cows with a decrease in milk yield greater than $10 \%$ underwent a physical examination by a trained herdsperson or by a FARMS veterinarian. The veterinarians from FARMS performed physical examinations and provided supervision and training of herd personnel performing clinical diagnosis and treatment of postpartum cows at least once a week. Additionally, FARMS veterinarians were called to assist or confirm clinical diagnosis or treatment of postpartum cows throughout the weekdays and weekends. Only disease events occurring during the first 28 DIM were used in this study. We first retrieved the electronic health records and then confirmed the information using the paper health records. Cows with mismatched information or with a disease diagnosis prepartum were excluded from the study. The health disorders evaluated were CDZ (dystocia, twins, stillbirths), metritis, ketosis, and mastitis. Calving difficulty was scored using a scale from 1 to $5(1=$ no assistance; $2=$ assistance by 1 person without the use of mechanical traction; $3=$ assistance by 2 or more people; $4=$ assistance with mechanical traction; $5=$ fetotomy or cesarean section). Cows that required assistance (score $\geq 2$ ) were considered to have dystocia. Stillbirth was defined as the birth of a dead calf or a calf that died within $24 \mathrm{~h}$ of birth. Metritis was characterized by presence of red-brownish watery fetid vaginal discharge within 21 DIM regardless of rectal temperature (Benzaquen et al., 2007). Detailed information about ketosis and mastitis is presented in a separate companion paper (Pérez-Báez et al., 2019). Cows suffering from metritis, ketosis, or mastitis were treated according to the farm standard operating procedure (https://vetmed-extension.sites.medinfo.ufl.edu/ files/2012/01/WEB_VERSSION_-2011-Dairy-Unit -Complete-SOPs-vers-11-07-01-with-Title-page.pdf).

\section{Statistical Analysis}

ANOVA for Repeated Measures. To evaluate the association of prepartum and postpartum DMI\%BW and EB with CDZ and metritis, we analyzed the data using ANOVA for repeated measures using the MIXED procedure of SAS version 9.4 (SAS Institute Inc., Cary, $\mathrm{NC}$ ). The data were divided into 2 periods, prepartum and postpartum. The dependent variables were pre- partum DMI\%BW or EB and postpartum DMI\%BW, $\mathrm{EB}$, and ECM. The independent variable was 1 of the 2 disorders (CDZ or metritis), which were modeled separately; cows that developed CDZ were compared with cows that did not develop CDZ, and cows that developed metritis were compared with cows that did not develop metritis. Cows that did not develop CDZ could have developed any other disorder, including metritis. Likewise, cows that did not develop metritis could have developed any other disorder. Other studies have used healthy cows as the comparison group (Huzzey et al., 2007). However, this would introduce selection bias; therefore, this could artificially increase the differences in the measures of DMI\%BW between the groups and inflate the estimates in a prediction model. Although the focus of this study was the comparison between cows affected with CDZ and metritis and unaffected cows, a comparison with healthy cows (i.e., cows that did not develop any disorder or disease diagnosed in the first 28 DIM) was also performed for comparison with the previous literature. Correlations between variables considered for inclusion in the models for this and the companion studies were assessed using Spearman's correlation using the CORR procedure in SAS and are presented in Supplemental Table S1 (https://doi.org/10.3168/jds.2018-15878). The models also included the fixed effects of parity (primigravid vs. multigravid), BCS in the last week prepartum $(<3.75$ vs. $\geq 3.75$; Gearhart et al., 1990), day relative to calving (prepartum $=\mathrm{d}-21$ to -1 ; postpartum $=\mathrm{d} 1$ to 28$)$, heat stress abatement (cool, hot without evaporative cooling, and hot with evaporative cooling), and 2-way interactions between disorder and other covariates, and cow was nested within experiment as a random effect. First-order autoregressive, compound symmetry, and unstructured covariance structures were tested, and the first-order autoregressive was selected because it resulted in the smallest Akaike's information criterion.

An as example, the initial model to evaluate the association between prepartum DMI\%BW and metritis was

$$
\begin{gathered}
\text { DMI\%BW prepartum }=\text { metritis }+ \text { day } \\
+ \text { heat stress abatement }+ \text { BCS }+ \text { parity }+ \text { metritis } \\
\times \text { day }+ \text { metritis } \times \text { heat stress abatement }+ \text { metritis } \\
\times \text { BCS }+ \text { metritis } \times \text { parity }+ \text { cow }(\text { experiment }) .
\end{gathered}
$$

The disorder of interest was forced into the model, but other variables were removed from the model by stepwise backward elimination according to Wald statistics criterion when $P>0.05$. When an interaction was detected $(P \leq 0.05)$, mean separation was assessed using the SLICE statement in the MIXED procedure, and 
multiple comparisons were performed using the TukeyKramer adjustment method in SAS.

Dystocia was first evaluated using all of the calving scores (1-5) but was then dichotomized (score $1=$ eutocia; score $\geq 2$ = dystocia) because the pattern of $\mathrm{DMI} \% \mathrm{BW}$ and $\mathrm{EB}$ was similar among cows with calving ease score $\geq 2$ (data not shown). Dystocia, twins, and stillbirths were first evaluated separately, but because the pattern of DMI\%BW and EB was similar (data not shown), they were combined into the variable CDZ to limit the number of variables presented in the paper. In addition, we analyzed absolute DMI as a dependent variable, and the results are shown in Supplemental Table S2 (https://doi.org/10.3168/jds.2018-15878).

An additional ANOVA for repeated measures was performed to evaluate which disease or disorder had the strongest association with prepartum DMI\%BW and EB. The dependent variables were prepartum DMI\%BW or EB. As independent variables we included all the diseases or disorders evaluated postpartum (i.e., CDZ, metritis, ketosis, digestive disorders, mastitis, and lameness) and other covariates such as parity, BCS, day relative to parturition, and heat stress abatement. Cow was nested within experiment as a random effect. Independent variables were removed from the model by stepwise backward elimination according to Wald statistics criterion when $P>0.05$.

Logistic Regression for Mixed Effects. To evaluate the use of prepartum DMI\%BW and EB as predictors of CDZ and metritis, each disease or disorder was considered the dependent variable and $\mathrm{DMI} \% \mathrm{BW}$ and EB were considered as independent variables. These data were analyzed by logistic regression with the GLIMMIX procedure of SAS. In this case, each disease or disorder was the dependent variable and the measures of prepartum DMI\%BW or EB were assessed separately in different models as independent variables. For this purpose, we created the variables average DMI\%BW or EB in the last 14,7 , and $3 \mathrm{~d}$ prepartum and reduction from $\mathrm{d}-8$ to -1 and from $\mathrm{d}-4$ to -1 . Univariable and multivariable models were performed. The univariable models included cow nested within experiment as a random variable. Measures of $\mathrm{DMI} \% \mathrm{BW}$ or EB with $P<0.20$ were selected for inclusion in the multivariable logistic regression models. Multivariable models also included parity (primigravid vs. multigravid), prepartum BCS (<3.75 vs. $\geq 3.75$ ), and heat stress abatement (cool, hot without evaporative cooling, and hot with evaporative cooling) and cow nested within experiment as a random effect. The model for metritis also included the fixed effects of CDZ and RP. Twoway interaction terms between significant measures of DMI\%BW and EB and other covariates were tested. A stepwise backward elimination was performed, and explanatory variables with $P>0.05$ according to the Wald statistics criterion were removed from the model.

When a measure of DMI\%BW or EB prepartum was found to be significant $(P \leq 0.05)$ after addition to the logistic regression model containing other covariates, we assessed their contribution to the predictive ability of the logistic regression model by comparing the area under the curve (AUC) of a receiver operating characteristic curve of the model with and without the significant measures of DMI\%BW or EB using the ROCCONTRAST statement of the LOGISTIC procedure of SAS as previously reported (Vergara et al., 2014). An AUC $\leq 0.50$ was considered noninformative, AUC between 0.50 and 0.70 was considered to have low accuracy, AUC between 0.70 and 0.90 was considered accurate, and AUC between 0.9 and 1.0 was considered highly accurate (Swets, 1988). Finally, we determined cut-off values for significant measures of DMI\%BW and EB prepartum for predicting CDZ and metritis using a receiver operating characteristic curve, and the cut-off with the greatest Youden's J statistic, which combines the values for sensitivity (Se) and specificity $(\mathbf{S p})$, was chosen. The Se, Sp, positive predicted value, negative predictive value, and overall accuracy of applying the cut-off to predict clinical mastitis and lameness were calculated. Statistical significance was considered when $P \leq 0.05$. The main limitation in this study was that the time-order of disease relative to DMI\%BW and ECM was inconsistent such that postpartum outcomes were measured before and after disease, which was diagnosed at variable intervals after calving.

\section{RESULTS}

The frequency of calving and uterine disorders diagnosed during the first $21 \mathrm{~d}$ postpartum is presented in Table 1. Results for the comparison between cows that developed CDZ and metritis and healthy cows are presented in the supplemental files (https://doi.org/10 .3168/jds.2018-15878). Spearman correlation coefficient is shown in Supplemental Table S1. The association of pre- and postpartum DMI with CDZ and metritis is shown in Supplemental Table S2. The association of pre- and postpartum DMI, DMI\%BW, EB, and ECM with CDZ and metritis compared with healthy cows is shown in Supplemental Tables S3 and S4, respectively. The association of pre- and postpartum DMI with CDZ and metritis is shown in Supplemental Figure S1. The association of pre- and postpartum DMI, DMI\%BW, $\mathrm{EB}$, and ECM with CDZ compared with healthy cows is shown in Supplemental Figure S2. The association of pre- and postpartum DMI, DMI\%BW, EB, and ECM with metritis compared with healthy cows is shown in Supplemental Figure S3. 

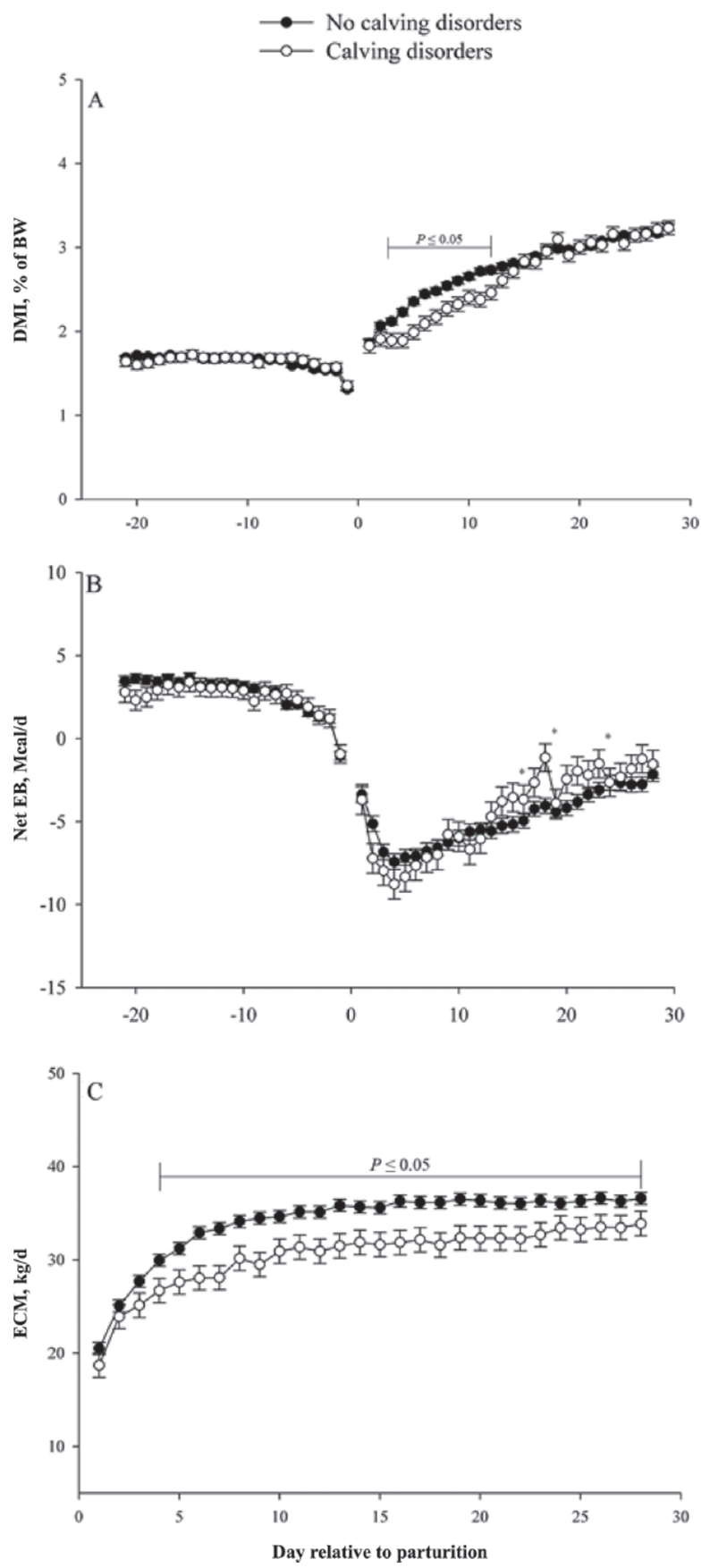

Figure 2. Association of calving disorders postpartum with (A) DMI as percentage of BW (DMI\%BW), (B) energy balance (EB $\mathrm{Mcal} / \mathrm{d}$ ) during the transition period (from -21 to $28 \mathrm{~d}$ ), and $(\mathrm{C})$ ECM $(\mathrm{kg} / \mathrm{d})$ during the first $28 \mathrm{~d}$ postpartum. Values are LSM \pm SEM. Prepartum DMI\%BW: calving disorders, $P=0.99$; day relative to parturition, $P<0.01$; interaction between calving disorders and day, $P=0.12$. Prepartum EB: calving disorders, $P=0.62$; day relative to parturition, $P<0.01$; interaction between calving disorders and day, $P=0.25$. Postpartum DMI\%BW: calving disorders, $P=0.07$; day relative to parturition, $P<0.01$; interaction between calving disorders and day, $P<0.01$. Postpartum EB: calving disorders, $P=0.56$; day relative to parturition, $P<0.01$; interaction between calving disorders and day, $P<0.01$. ECM: calving disorders, $P<0.01$; day relative to parturition, $P<0.01$; interaction between calving disorders and day, $P<0.01 .{ }^{*} P \leq 0.05$
Association of Prepartum DMI\%BW and EB with CDZ

Calving disorders were not associated with prepartum DMI\%BW (Figure 2A) or EB (Figure 2B; Table $2)$.

\section{Prepartum DMI\%BW and EB as Predictors of CDZ}

None of the measures of $\mathrm{DMI} \% \mathrm{BW}$ and $\mathrm{EB}$ were found to be significant predictors of CDZ in the univariable or multivariable models $(P>0.10)$.

\section{Association of Postpartum DMI\%BW, $E B$, and $E C M$ with $C D Z$}

The association between CDZ and postpartum DMI\%BW and postpartum EB was dependent on time (Table 2). Cows that developed CDZ had lesser DMI\%BW from d 3 to $12(P \leq 0.05$; Figure $2 \mathrm{~A})$ but greater $\mathrm{EB}$ on $\mathrm{d} 15(P=0.03), 18(P<0.01)$, and 23 $(P=0.05)$ compared with cows that did not develop CDZ (Figure 2B). The ECM for cows that developed CDZ was lesser $(P<0.01)$ compared with cows that did not develop CDZ (Table 2), and an interaction ( $P$ $<0.01$ ) between CDZ and day on ECM showed that cows that developed CDZ had lesser ECM compared with cows that did not develop CDZ from d 4 to 27 postpartum $(P \leq 0.05$; Figure $2 \mathrm{C})$.

\section{Association of Prepartum DMI\%BW and EB with Metritis}

Metritis was associated with prepartum DMI\%BW and EB (Table 3). Cows that developed metritis had lesser prepartum DMI\%BW $(P=0.01)$ compared with cows that did not develop metritis (Table 3; Figure 3A) and had lesser EB $(P=0.02)$ during the prepartum period compared with cows that did not develop metritis (Table 3; Figure 3B).

\section{Prepartum DMI\%BW and EB as Predictors of Metritis}

Of the covariates evaluated, CDZ and RP were the only significant predictors of metritis. Cows with CDZ had increased odds of developing metritis compared with cows that did not have $\mathrm{CDZ}$ (odds ratio, OR: $2.7 ; 95 \%$ CI: $1.5-4.7 ; P<0.01)$. Cows with RP had increased odds of developing metritis compared with cows that did not have RP (OR: $46.3 ; 95 \%$ CI: $10.2-208.9 ; P$ $<0.01)$. The average DMI\%BW and EB during the last 3 d prepartum were significant predictors $(P \leq 0.05)$ of metritis in both the univariable and multivariable models. In the multivariable model, there was an $8 \%$ increase in the odds of having metritis for each 0.1-per- 
Table 2. Association of prepartum ( -21 to $-1 \mathrm{~d}$ ) and postpartum ( 1 to $28 \mathrm{~d})$ DMI as percentage of BW (DMI\%BW), energy balance (EB), and ECM with calving disorders according to multivariable analysis ${ }^{1}$

\begin{tabular}{|c|c|c|c|c|c|c|c|c|c|c|}
\hline Item & \multicolumn{2}{|c|}{ Prepartum } & \multicolumn{3}{|c|}{$P$-value } & \multicolumn{2}{|c|}{ Postpartum } & \multicolumn{3}{|c|}{$P$-value } \\
\hline EB, Mcal/d & $2.5 \pm 0.4$ & $2.7 \pm 0.2$ & 0.62 & $<0.01$ & 0.25 & $-4.4 \pm 0.7$ & $-4.8 \pm 0.4$ & 0.56 & $<0.01$ & $<0.01$ \\
\hline ECM, kg/d & - & - & - & - & - & $30.6 \pm 1.1$ & $34.0 \pm 0.6$ & $<0.01$ & $<0.01$ & $<0.01$ \\
\hline
\end{tabular}

${ }^{1} \mathrm{CDZ}=$ calving disorders; day $=$ day relative to parturition; $\mathrm{CDZ} \times \mathrm{D}=$ interaction between $\mathrm{CDZ}$ and day. Values are LSM $\pm \mathrm{SEM}$.

centage point decrease in the average $\mathrm{DMI} \% \mathrm{BW}$ in the last $3 \mathrm{~d}$ prepartum and for each 1-Mcal decrease in the average EB in the last $3 \mathrm{~d}$ prepartum (Table 4). The average DMI\%BW ranged from 0.3 to $2.9 \% / \mathrm{d}$, and the average EB ranged from -12.5 to $17.4 \mathrm{Mcal} / \mathrm{d}$.

When the average $\mathrm{DMI} \% \mathrm{BW}$ and $\mathrm{EB}$ in the last $3 \mathrm{~d}$ prepartum were included individually in the metritis-predicting models containing $\mathrm{RP}$ and $\mathrm{CDZ}$, the AUC increased from 0.67 (95\% CI: $0.62-0.71$ ) to 0.72 (95\% CI: $0.68-0.76)$ and from 0.67 to 0.72 (95\% CI: 0.68-0.76), respectively, and the differences between the areas were statistically significant $(P \leq 0.05)$. The average $\mathrm{DMI} \% \mathrm{BW}$ and $\mathrm{EB}$ during the last $3 \mathrm{~d}$ prepartum produced significant $(P<0.01)$ cut-offs to predict metritis, which were $\leq 1.6 \% / \mathrm{d}$ and $\leq 2.5 \mathrm{Mcal} / \mathrm{d}$, respectively (Table 5).

\section{Association of Postpartum DMI\%BW, EB, and ECM with Metritis}

Cows that developed metritis had lesser postpartum DMI\%BW $(P<0.01)$ compared with cows that did not develop metritis (Table 3$)$, and an interaction $(P$ $<0.01$ ) between metritis and day showed that postpartum DMI\%BW for cows that developed metritis was lesser than for cows that did not develop metritis from d 1 to 26 and on d 28 postpartum (Figure 3A). The association between metritis and postpartum EB was dependent on time (Table 3). Cows that developed metritis had greater negative EB from d 2 to 5 and from d 7 to 11 and lesser negative EB from d 25 to 27 compared with cows that did not develop metritis (Figure 3B). The ECM for cows that developed metritis was lesser $(P<0.01)$ compared with that for cows that did not develop metritis (Table 3 ), and an interaction $(P<0.01)$ between metritis and day on ECM showed that cows that developed metritis had lesser ECM from d 3 to 28 postpartum than cows that did not develop metritis $(P \leq 0.05$; Figure $3 \mathrm{C})$.

\section{Association of Prepartum DMI\%BW and EB with Postpartum Disorders}

When all diseases or disorders were included in the model, the association between metritis and prepartum DMI\%BW lost significance $(P=0.08)$, but metritis remained associated with prepartum $\mathrm{EB}(P=0.04)$, and the direction of the association was the same as reported herein. Ketosis was associated with prepartum $\mathrm{DMI} \% \mathrm{BW}$ and EB $(P \leq 0.01)$, and mastitis was associated with prepartum DMI\%BW $(P=0.05$; Table 6$)$.

\section{DISCUSSION}

The objectives of this study were to evaluate the association of prepartum and postpartum DMI\%BW and EB with CDZ and metritis and to evaluate prepartum $\mathrm{DMI} \% \mathrm{BW}$ and $\mathrm{EB}$ as predictors of $\mathrm{CDZ}$ and metritis. It was hypothesized that DMI\%BW and $\mathrm{EB}$ during the transition period would be associated with CDZ and metritis. Herein, we showed that prepartum DMI\%BW or EB were not associated with CDZ, but cows that developed metritis had decreased overall DMI\%BW and EB prepartum. Furthermore, the average DMI\%BW and $\mathrm{EB}$ in the last $3 \mathrm{~d}$ prepartum were significant explanatory variables for metritis, and the addition of

Table 3. Association of prepartum ( -21 to $-1 \mathrm{~d})$ and postpartum ( 1 to $28 \mathrm{~d})$ DMI as percentage of BW (DMI\%BW), energy balance (EB), and ECM with metritis according to multivariable analysis ${ }^{1}$

\begin{tabular}{|c|c|c|c|c|c|c|c|c|c|c|}
\hline \multirow[b]{2}{*}{ Item } & \multicolumn{2}{|c|}{ Prepartum } & \multicolumn{3}{|c|}{$P$-value } & \multicolumn{2}{|c|}{ Postpartum } & \multicolumn{3}{|c|}{$P$-value } \\
\hline & MET & No MET & MET & Day & $\mathrm{MET} \times \mathrm{D}$ & MET & No MET & MET & Day & $\mathrm{MET} \times \mathrm{D}$ \\
\hline
\end{tabular}

${ }^{1} \mathrm{MET}=$ metritis; day $=$ day relative to parturition; MET $\times \mathrm{D}=$ interaction between metritis and day. Values are LSM $\pm \mathrm{SEM}$. 

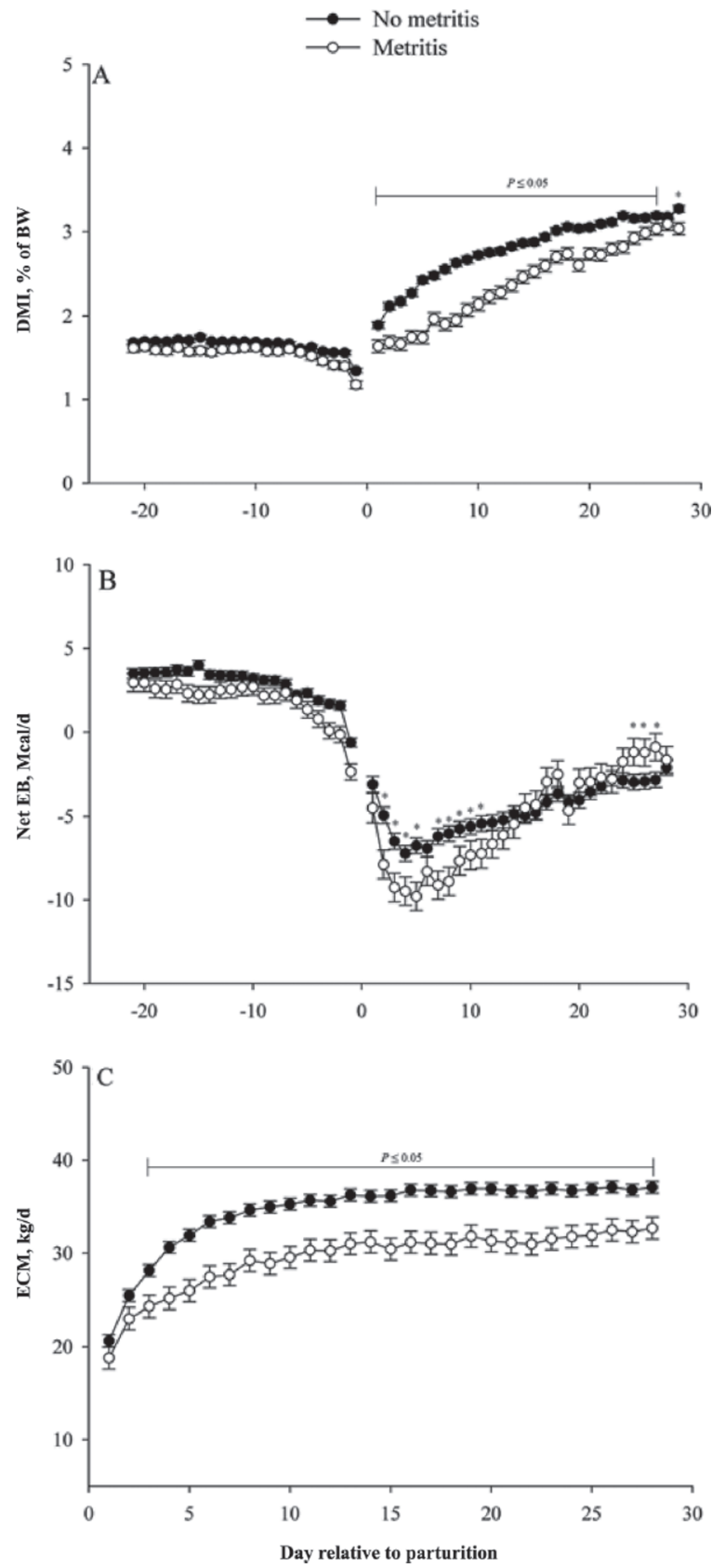

Figure 3. Association of metritis postpartum with (A) DMI as percentage of BW (DMI\%BW), (B) energy balance (EB, Mcal/d) during the transition period (from -21 to $28 \mathrm{~d}$ ), and (C) ECM $(\mathrm{kg} / \mathrm{d}$ ) during the first $28 \mathrm{~d}$ postpartum. Values are LSM \pm SEM. Prepartum DMI\%BW: metritis, $P=0.01$; day relative to parturition, $P<0.01$; interaction between metritis and day, $P=0.33$. Prepartum EB: metritis, $P=0.02$; day relative to parturition, $P<0.01$; interaction between metritis and day, $P=0.09$. Postpartum DMI\%BW: metritis, $P<0.01$; day relative to parturition, $P<0.01$; interaction between metritis and day, $P<0.01$. Postpartum EB: metritis, $P=0.37$; day relative to parturition, $P<0.01$; interaction between metritis and day, $P<$ 0.01. ECM: metritis, $P<0.01$; day relative to parturition, $P<0.01$; interaction between metritis and day, $P<0.01$. The main limitation in this study was that the time-order of disease relative to DMI and milk yield was inconsistent such that postpartum outcomes were measured before and after disease, which was diagnosed at variable intervals after calving. ${ }^{*} P \leq 0.05$.
DMI\%BW and EB in the last $3 \mathrm{~d}$ prepartum to a model containing CDZ and RP significantly increased the predictive ability of the model. Postpartum DMI\%BW and ECM was decreased for cows that developed CDZ and metritis. In addition, cows that developed metritis had greater negative EB from d 2 to 9.

Previous studies have evaluated the association of prepartum absolute DMI with dystocia (Proudfoot et al., 2009) and metritis (Huzzey et al., 2007; Schirmann et al., 2016). Proudfoot et al. (2009) found that cows that had dystocia consumed $12 \%$ less DMI during the last $2 \mathrm{~d}$ prepartum compared with cows with eutocia. Conversely, we observed that DMI (Supplemental Table S2 and Supplemental Figure S1, panel A; https: //doi.org/10.3168/jds.2018-15878), DMI\%BW, and EB were similar among cows that did and did not have CDZ (dystocia, twins, and stillbirths) throughout the entire prepartum period. Likewise, measures of $\mathrm{DMI} \% \mathrm{BW}$ or EB prepartum were not significant explanatory variables for CDZ. It is not clear why the discrepancy between our findings and previous findings exists (Proudfoot et al., 2009). One possibility is differences in the definition of dystocia. In the study by Proudfoot et al. (2009), cows that required 2 or more people to deliver the calf were compared with cows that required no assistance, whereas cows that required only 1 person to deliver the calf were excluded. Nonetheless, even when we compared all of the calving scores, we could not observe an effect of higher calving scores $(>2)$ on prepartum DMI, DMI\%BW, and $\mathrm{EB}$, and we obtained similar results when it was compared with healthy cows (Supplemental Table S3; https://doi.org/ 10.3168/jds.2018-15878). Herein, we included a large number of cows with dystocia $(\mathrm{n}=79)$, which provides considerable confidence in the association of prepartum $\mathrm{DMI} \% \mathrm{BW}$ and EB with dystocia. Moreover, we found no association of prepartum DMI\%BW and EB with twins or stillbirths when compared with cows that did not develop twins or stillbirths. Nonetheless, when cows that had CDZ were compared with healthy cows, cows that had CDZ had lesser prepartum DMI\%BW and EB (Supplemental Table S3 and Supplemental Figure S2, panels B and C; https://doi.org/10.3168/jds.2018 -15878). When evaluated separately, cows that had twins showed lesser prepartum DMI\%BW and EB than healthy cows carrying singletons (data not shown), and cows that had dystocia and stillbirths had similar prepartum DMI\%BW and EB compared with healthy cows (data not shown). This finding, although not observable at the herd level because cows that do not have twins may have other disorders that affect DMI, may be a consequence of greater discomfort in cows carrying twins compared with cows carrying singletons. To our knowledge, this is the first study to evaluate DMI\%BW 
Table 4. Effect of each 0.1-percentage point decrease in average DMI as a percentage of BW (DMI\%BW) and each unit decrease in average energy balance (EB) in the last $3 \mathrm{~d}$ prepartum on diseases or disorders in the first $28 \mathrm{~d}$ postpartum

\begin{tabular}{lccccccc}
\hline & \multicolumn{3}{c}{ DMI, \% of BW } & & \multicolumn{3}{c}{$\mathrm{EB}, \mathrm{Mcal} / \mathrm{d}$} \\
\cline { 2 - 5 } \cline { 6 - 8 } Disorder & $\mathrm{OR}^{1}$ & $95 \% \mathrm{CI}$ & $P$-value & & OR & $95 \% \mathrm{CI}$ & $P$-value \\
\hline CDZ $^{2}$ & 1.04 & $0.98-1.09$ & 0.17 & & 1.02 & $0.96-1.07$ & 0.57 \\
Metritis & 1.08 & $1.02-1.14$ & $<0.01$ & & 1.08 & $1.03-1.14$ & $<0.01$ \\
\hline
\end{tabular}

${ }^{1}$ Odds ratio.

${ }^{2}$ Calving disorders (twins, stillbirth, dystocia).

and EB prepartum in cows that developed twins or stillbirths. Liboreiro et al. (2015) compared daily rumination time prepartum in cows that had twins and cows that had singletons and found no difference, but cows that had stillbirths had lower rumination time during the majority of the prepartum period than cows that had live calves, which may indicate a decrease in DMI prepartum in cows that had stillbirths. Nonetheless, rumination time was found not to be correlated with DMI because of the negative correlation between rumination time and feeding time (Schirmann et al., 2012); therefore, rumination time may be affected without affecting DMI.

During the postpartum period, cows that had CDZ had lesser DMI\%BW and greater negative EB than cows that did not have CDZ. Proudfoot et al. (2009) showed that cows that had dystocia had similar DMI during the first 24 and $48 \mathrm{~h}$ after calving and no differences in meal sizes after calving. Although we did not find any difference between groups in DMI\%BW on d 1 after calving, the DMI\%BW was lesser starting on $\mathrm{d}$ 3 , and DMI was lesser starting on d 2 (Supplemental Figure S1, panel A; https://doi.org/10.3168/jds.2018 -15878), and such differences continued until d 12 . The negative association between CDZ and DMI\%BW may be a consequence of pain associated with dystocia and the predisposition of cows with dystocia to have vulvovaginal lacerations (Vieira-Neto et al., 2016), which may decrease the cow's appetite in the first few days postpartum because of the associated pain and discomfort. In addition, CDZ are a risk factor for metritis, which may further decrease DMI\%BW because of the associated clinical signs of the disease, such as fever and lethargy, and the associated pain (Stojkov et al., 2015).
Postpartum EB deficit in cows that had CDZ was similar to that in cows that did not have CDZ during the first day of postpartum, and then the deficit was lesser in some days after 2 wk relative to parturition. This was mainly because cows that had CDZ had lesser ECM throughout the observation period but recovered DMI after 14 DIM. Nonetheless, when cows that had CDZ were compared with healthy cows, there was a greater EB deficit postpartum in cows that had CDZ in the first $2 \mathrm{wk}$ postpartum because the differences in $\mathrm{DMI} \% \mathrm{BW}$ were more pronounced.

Cows that developed metritis had decreased DMI\%BW and EB prepartum compared with cows that did not develop metritis. Nonetheless, after including all diseases in the model, DMI\%BW lost significance but metritis was still associated with prepartum EB. Huzzey et al. (2007) reported that cows with severe metritis (putrid vaginal discharge with a red-brownish color that was watery and foul smelling and 1 recording of fever $\geq 39.5^{\circ} \mathrm{C}$ ) had decreased DMI during the last 2 wk prepartum, with a clear divergence from healthy cows starting on d -7 . Schirmann et al. (2016) observed that cows that developed metritis concurrent with subclinical ketosis had a decrease in DMI from d -7 to -2 compared with healthy cows. Similar to previous literature, when we compared cows that developed metritis with healthy cows, prepartum DMI was lesser for metritic cows than for healthy cows (Supplemental Table S4; https://doi.org/10.3168/jds.2018-15878), with a clear divergence starting on $\mathrm{d}-5$ (Supplemental Figure S3, panel A; https://doi.org/10.3168/jds.2018 -15878). As mentioned previously, our study is focused on the observable differences in prepartum DMI\%BW and EB between cows that did and did not have metri-

Table 5. Cut-offs of DMI as percentage of BW (DMI\%BW) and energy balance (EB) to predict metritis postpartum ${ }^{1}$

\begin{tabular}{lcccccrrrr}
\hline Item & Cut-off & Se, $\%$ & Sp, $\%$ & PPV, $\%$ & NPV, $\%$ & Acc, $\%$ & AUC & $P$-value \\
\hline DMI\%BW & $\leq 1.6$ & 78 & 37 & 28 & 84 & 46 & 0.58 & 0.01 \\
EB, Mcal/d & $\leq 2.5$ & 83 & 38 & 29 & 88 & 48 & 0.59 & $<0.01$ \\
\hline
\end{tabular}

${ }^{1} \mathrm{Se}=$ sensitivity $\mathrm{Sp}=$ specificity $; \mathrm{PPV}=$ positive predicted value $\mathrm{NPV}=$ negative predictive value Acc $=$ accuracy; AUC $=$ area under the curve. 
Table 6. Association of prepartum ( -21 to $-1 \mathrm{~d})$ DMI as percentage of BW (DMI\%BW) and energy balance (EB) with postpartum disorders ${ }^{1}$

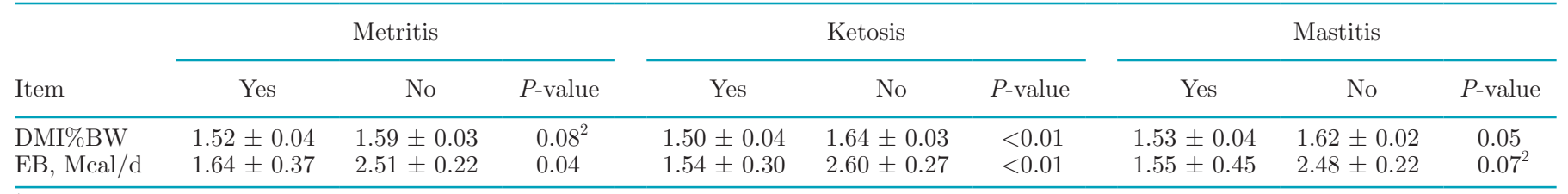

${ }^{1} P$-values $\leq 0.05$ were considered significant.

${ }^{2}$ Variable was not included in the final model. Values (LSM, SEM, and $P$-values) were derived from the iteration before the variable was removed from the final model.

tis. In a herd, cows that do not develop metritis could develop any other disease or disorder that is associated with decreased DMI, DMI\%BW, and EB prepartum, such as ketosis and mastitis (Pérez-Báez et al., 2019); therefore, excluding cows that develop other conditions could inflate the measures of association. This is of particular relevance for the prediction model. Huzzey et al. (2007) reported that the odds of severe metritis increased 2.87 times for each $1-\mathrm{kg}$ decrease in DMI during the last week prepartum. In our study, the effect sizes were small (an $8 \%$ increase in the odds of having metritis with each unit decrease in the measures of both DMI\%BW and $\mathrm{EB}$ ), and the addition of $\mathrm{DMI} \% \mathrm{BW}$ and $\mathrm{EB}$ in the last $3 \mathrm{~d}$ prepartum to a metritis-predicting model significantly increased the predictive ability of the models as evaluated by the AUC, indicating that DMI\%BW and $\mathrm{EB}$ prepartum were contributors to the development of metritis even when accounting for other variables such as CDZ and RP. In addition, we determined cut-offs for DMI\%BW and EB to see whether they could be used solely as a predictor of metritis, and the cut-offs resulted in moderate Se (78-83\%) and low Sp (37-38\%). In a previous study, Ospina et al. (2010b) reported low Se (37\%) and moderate Sp $(80 \%)$ for a prepartum NEFA cut-off of $0.37 \mathrm{mEq} / \mathrm{L}$ to predict metritis, RP, or both. Therefore, our cut-off is more useful for identifying the majority of the cows that will develop metritis, whereas that of Ospina et al. (2010b) is more useful for identifying cows that will not develop metritis. Perhaps a combination of DMI\%BW or EB and NEFA prepartum could results in improved accuracy of predicting metritis. Others have used a health index score based on rumination time and physical activity during the postpartum period (i.e., d -5 to 2 relative to clinical diagnosis) to identify cows with metritis and observed an Se of $55 \%$, but Sp was not reported (Stangaferro et al., 2016). Huzzey et al. (2007) suggested that the decrease in DMI prepartum could be attributed to decreased cow dominance at the feed bunk. Nonetheless, it was later observed that cows that develop metritis are actually more dominant at the feed bunk, which may affect their DMI because the time spent protecting the feed bunk may reduce eating time (Chebel et al., 2016).

Cows with metritis also had lesser DMI\%BW, EB, and ECM during the postpartum period. Previous research has shown a decrease in DMI during the postpartum period (Huzzey et al., 2007). The onset of infection leads to the release of cytokines and chemokines such as IL-1 $\beta$, IL-6, and TNF- $\alpha$ that will induce anorexia (Plata-Salamán et al., 1996). Anorexia may worsen the EB and lead to body fat mobilization and ketone body production, which may further decrease feed intake (Visinoni et al., 2012). Cows with metritis had greater negative EB during postpartum compared with cows that did not develop metritis from d 2 until d 9; then, EB recovered and was actually less negative for metritic cows from d 25 to 27. This pattern of EB occurred because cows with metritis had lesser ECM throughout the observation period but recovered DMI at the end of the observation period. It is interesting that the recovery in DMI\%BW for cows with CDZ and metritis was not accompanied by a comparable increase in ECM. This finding indicates that CDZ and metritis are associated with long-term changes in nutrient partitioning. During infection and inflammation, peripheral insulin resistance decreases and mammary glands reduce glucose uptake, which makes glucose more available to leukocytes to fight infection but leads to decreased milk yield (Bradford et al., 2015; Baumgard et al., 2017). It is interesting that the changes in the metabolism of the mammary gland persisted long after the initial trauma (i.e., CDZ) or infection (i.e., metritis) had occurred, which deserves further investigation to better understand the effect of infection and inflammation on long-term nutrient partitioning.

A limitation from this study is that data were collected from different experiments over the years. Because different observers collected subjective data such as BCS in each trial, agreement among observers could not be compared; also, treatments had been applied in each trial (i.e., heat stress abatement), which had to be controlled for in the statistical analysis. Another limitation is that the association of metritis with DMI\%BW, 
$\mathrm{EB}$, and ECM during the postpartum period could not be evaluated before and after metritis diagnosis because dividing the data would have resulted in reduced sample size per day, therefore increasing the standard errors or producing unreliable standard errors. As an example, cows that developed metritis on $\mathrm{d} 2$ would have only $1 \mathrm{~d} \backslash$ of DMI before the disease diagnosis but $26 \mathrm{~d}$ of DMI after the disease diagnosis, whereas in cows diagnosed with metritis from d 3 to 12 the number of days of DMI before the disease diagnosis would increase but the number of days of DMI after the disease diagnosis would decrease. In addition, we could not ascertain the day cows developed metritis because cows were not examined daily. Last, even if we divided our data before and after disease diagnosis, we could not infer causation because cows were not randomly assigned to develop metritis. Hence, herein we present the association between metritis development and DMI\%BW and EB pre- and postpartum.

\section{CONCLUSIONS}

In summary, CDZ was not associated with prepartum DMI\%BW or EB but was associated with a decrease in postpartum DMI\%BW and ECM. Metritis was associated with a decrease in prepartum DMI\%BW and EB. The average DMI\%BW and EB in the last $3 \mathrm{~d}$ prepartum were significant explanatory variables for metritis, and $\mathrm{DMI} \% \mathrm{BW}$ and $\mathrm{EB}$ in the last $3 \mathrm{~d}$ prepartum significantly increased the predictive ability of metritispredicting models. Prepartum cut-offs for DMI\%BW and EB to predict metritis were established and had moderate Se and low Sp. In addition, metritis was associated with a decrease in postpartum DMI\%BW and ECM and a greater negative EB. The results of this study give a better understating of the role DMI plays during the transition period; namely, when DMI\%BW decreases and the deficit of EB increases, the risk of metritis increases, although the increase was small. The main limitation in this study was that the time-order of disease relative to DMI\%BW and ECM was inconsistent such that postpartum outcomes were measured before and after disease, which was diagnosed at variable intervals after calving. In summary, DMI\%BW and EB prepartum are significant but minor contributors to metritis development postpartum and cannot be used reliably to identify cows that will develop metritis postpartum.

\section{ACKNOWLEDGMENTS}

We thank the College of Veterinary Medicine at the University of Florida (Gainesville) for the Graduate
School Fellowship award that supported the PhD student J. Pérez-Báez.

\section{REFERENCES}

Armstrong, D. V. 1994. Heat stress interaction with shade and cooling. J. Dairy Sci. 77:2044-2050.

Baumgard, L. H., R. J. Collier, and D. E. Bauman. 2017. A 100-year review: Regulation of nutrient partitioning to support lactation. J. Dairy Sci. 100:10353-10366.

Beam, S. W., and W. R. Butler. 1999. Effects of energy balance on follicular development and first ovulation in postpartum dairy cows. J. Reprod. Fertil. Suppl. 54:411-424.

Benzaquen, M. E., C. A. Risco, L. F. Archbald, P. Melendez, M. J. Thatcher, and W. W. Thatcher. 2007. Rectal temperature, calving-related factors, and the incidence of puerperal metritis in postpartum dairy cows. J. Dairy Sci. 90:2804-2814.

Bradford, B. J., K. Yuan, J. K. Farney, L. K. Mamedova, and A. J. Carpenter. 2015. Invited review: Inflammation during the transition to lactation: New adventures with an old flame. J. Dairy Sci. 98:6631-6650.

Chebel, R. C., P. R. Silva, M. I. Endres, M. A. Ballou, and K. L. Luchterhand. 2016. Social stressors and their effects on immunity and health of periparturient dairy cows. J. Dairy Sci. 99:32173228.

Correa, M. T., H. Erb, and J. Scarlett. 1993. Path analysis for seven postpartum disorders of Holstein cows. J. Dairy Sci. 76:1305-1312.

Dikmen, S., and P. J. Hansen. 2009. Is the temperature-humidity index the best indicator of heat stress in lactating dairy cows in a subtropical environment? J. Dairy Sci. 92:109-116.

do Amaral, B. C., E. E. Connor, S. Tao, J. Hayen, J. Bubolz, and G. E. Dahl. 2009. Heat-stress abatement during the dry period: Does cooling improve transition into lactation? J. Dairy Sci. 92:59885999 .

do Amaral, B. C., E. E. Connor, S. Tao, J. Hayen, J. Bubolz, and G. E. Dahl. 2011. Heat stress abatement during the dry period influences hepatic gene expression and improves immune status during the transition period of dairy cows. J. Dairy Sci. 94:86-96.

Drackley, J. K. 1999. Biology of dairy cows during the transition period: The final frontier? J. Dairy Sci. 82:2259-2273.

Ferguson, J. D., D. T. Galligan, and N. Thomsen. 1994. Principal descriptors of body condition score in Holstein cows. J. Dairy Sci. 77:2695-2703.

French, P. D. 2006. Dry matter intake and blood parameters of nonlactating Holstein and Jersey cows in late gestation. J. Dairy Sci. 89:1057-1061.

Gearhart, M. A., C. R. Curtis, H. N. Erb, R. D. Smith, C. J. Sniffen, L. E. Chase, and M. D. Cooper. 1990. Relationship of changes in condition score to cow health in Holsteins. J. Dairy Sci. 73:31323140.

Gomes, G. C. 2014. Effects of evaporative cooling prepartum and vitamin E supplementation on performance and immune function of Holstein cows under heat stress conditions. MS Dissertation. Department of Animal Sciences, University of Florida, Gainesville.

Greco, L. 2014. Effects of dietary polyunsaturated fatty acids on lactation performance, tissue gene expression, and reproduction in dairy cows. PhD Dissertation. Department of Animal Sciences, University of Florida, Gainesville.

Gröhn, Y. T., S. W. Eicker, V. Ducrocq, and J. A. Hertl. 1998. Effect of diseases on the culling of Holstein dairy cows in New York State. J. Dairy Sci. 81:966-978.

Gross, J., H. A. van Dorland, R. M. Bruckmaier, and F. J. Schwarz. 2011. Performance and metabolic profile of dairy cows during a lactational and deliberately induced negative energy balance with subsequent realimentation. J. Dairy Sci. 94:1820-1830.

Grummer, R. R., D. G. Mashek, and A. Hayirli. 2004. Dry matter intake and energy balance in the transition period. Vet. Clin. North Am. Food Anim. Pract. 20:447-470.

Hammon, D. S., I. M. Evjen, T. R. Dhiman, J. P. Goff, and J. L. Walters. 2006. Neutrophil function and energy status in Holstein 
cows with uterine health disorders. Vet. Immunol. Immunopathol. 113:21-29.

Hayirli, A., R. R. Grummer, E. V. Nordheim, and P. M. Crump. 2002. Animal and dietary factors affecting feed intake during the prefresh transition period in Holsteins. J. Dairy Sci. 85:3430-3443.

Huzzey, J. M., D. M. Veira, D. M. Weary, and M. A. G. von Keyserlingk. 2007. Prepartum behavior and dry matter intake identify dairy cows at risk for metritis. J. Dairy Sci. 90:3220-3233.

Kimura, K., J. P. Goff, M. E. J. Kehrli, and T. A. Reinhardt. 2002 Decreased neutrophil function as a cause of retained placenta in dairy cattle. J. Dairy Sci. 85:544-550.

Liboreiro, D. N., K. S. Machado, P. R. Silva, M. M. Maturana, T. K. Nishimura, A. P. Brandão, M. I. Endres, and R. C. Chebel 2015. Characterization of peripartum rumination and activity of cows diagnosed with metabolic and uterine diseases. J. Dairy Sci. 98:6812-6827.

Mahnani, A., A. Sadeghi-Sefidmazgi, and V. E. Cabrera. 2015. Consequences and economics of metritis in Iranian Holstein dairy farms. J. Dairy Sci. 98:6048-6057.

Martinez, N., C. A. Risco, F. S. Lima, R. S. Bisinotto, L. F. Greco, E. S. Ribeiro, F. Maunsell, K. Galvão, and J. E. Santos. 2012. Evaluation of peripartal calcium status, energetic profile, and neutrophil function in dairy cows at low or high risk of developing uterine disease. J. Dairy Sci. 95:7158-7172.

Martinez, N., R. M. Rodney, E. Block, L. L. Hernandez, C. D. Nelson, I. J. Lean, and J. E. P. Santos. 2018. Effects of prepartum dietary cation-anion difference and source of vitamin D in dairy cows: Health and reproductive responses. J. Dairy Sci. 101:2563-2578.

McArt, J. A., D. V. Nydam, and G. R. Oetzel. 2012. Epidemiology of subclinical ketosis in early lactation dairy cattle. J. Dairy Sci. 95:5056-5066.

NRC. 2001. Nutrient Requirements of Dairy Cattle. 7th ed. National Academy Press, Washington, DC.

Ospina, P. A., D. V. Nydam, T. Stokol, and T. R. Overton. 2010a. Association between the proportion of sampled transition cows with increased nonesterified fatty acids and beta-hydroxybutyrate and disease incidence, pregnancy rate, and milk production at the herd level. J. Dairy Sci. 93:3595-3601.

Ospina, P. A., D. V. Nydam, T. Stokol, and T. R. Overton. 2010b. Evaluation of nonesterified fatty acids and $\beta$-hydroxybutyrate in transition dairy cattle in the northeastern United States: Critical thresholds for prediction of clinical diseases. J. Dairy Sci. 93:546554

Overton, M., and J. Fetrow. 2008. Economics of postpartum uterine health. Pages 39-43 in Proc. Dairy Cattle Reproduction Council Convention, Omaha, NE. Dairy Cattle Reproduction Council, Hartland, WI.

Pérez-Báez, J., C. A. Risco, R. C. Chebel, G. C. Gomes, L. F. Greco, S. Tao, I. M. Thompson, B. C. do Amaral, M. G. Zenobi, N Martinez, C. R. Staples, G. E. Dahl, J. A. Hernández, J. E. P. Santos, and K. N. Galvão. 2019. Association of dry matter intake and energy balance pre- and postpartum with health disorders postpartum: Part II. Ketosis and clinical mastitis. J. Dairy Sci. 102:9151-9164. https://doi.org/10.3168/jds.2018-15879.

Plata-Salamán, C. R., G. Sonti, J. P. Borkoski, C. D. Wilson, and J. M. H. French-Mullen. 1996. Anorexia induced by chronic central administration of cytokines at estimated pathophysiological concentrations. Physiol. Behav. 60:867-875.

Proudfoot, K. L., J. M. Huzzey, and M. A. G. von Keyserlingk. 2009. The effect of dystocia on the dry matter intake and behavior of Holstein cows. J. Dairy Sci. 92:4937-4944.

Raboisson, D., M. Mounié, and E. Maigné. 2014. Diseases, reproductive performance, and changes in milk production associated with subclinical ketosis in dairy cows: A meta-analysis and review. J. Dairy Sci. 97:7547-7563.

Ribeiro, E. S., F. S. Lima, L. F. Greco, R. S. Bisinotto, A. P. A. Monteiro, M. Favoreto, H. Ayres, R. S. Marsola, N. Martinez, W. W. Thatcher, and J. E. P. Santos. 2013. Prevalence of periparturient diseases and effects on fertility of seasonally calving grazing dairy cows supplemented with concentrates. J. Dairy Sci. 96:5682-5697.

Santos, J. E. P., R. L. A. Cerri, M. A. Ballou, G. E. Higginbotham, and J. H. Kirk. 2004. Effect of timing of first clinical mastitis occurrence on lactational and reproductive performance of Holstein dairy cows. Anim. Reprod. Sci. 80:31-45.

Schirmann, K., N. Chapinal, D. M. Weary, W. Heuwieser, and M. A. von Keyserlingk. 2012. Rumination and its relationship to feeding and lying behavior in Holstein dairy cows. J. Dairy Sci. 95:32123217.

Schirmann, K., D. M. Weary, W. Heuwieser, N. Chapinal, R. L. Cerri, and M. A. von Keyserlingk. 2016. Short communication: Rumination and feeding behaviors differ between healthy and sick dairy cows during the transition period. J. Dairy Sci. 99:9917-9924.

Sepúlveda-Varas, P., D. M. Weary, M. Noro, and M. A. G. von Keyserlingk. 2015. Transition diseases in grazing dairy cows are related to serum cholesterol and other analytes. PLoS One 10:e0122317.

Stangaferro, M. L., R. Wijma, L. S. Caixeta, M. A. Al-Abri, and J. O. Giordano. 2016. Use of rumination and activity monitoring for the identification of dairy cows with health disorders: Part III. Metritis. J. Dairy Sci. 99:7422-7433.

Stojkov, J., M. A. von Keyserlingk, J. N. Marchant-Forde, and D. M. Weary. 2015. Assessment of visceral pain associated with metritis in dairy cows. J. Dairy Sci. 98:5352-5361.

Suriyasathaporn, W., C. Heuer, E. N. Noordhuizen-Stassen, and Y. H. Schukken. 2000. Hyperketonemia and the impairment of udder defense: A review. Vet. Res. 31:397-412.

Swets, J. A. 1988. Measuring the accuracy of diagnostic systems. Science 240:1285-1293.

Tao, S., J. W. Bubolz, B. C. do Amaral, I. M. Thompson, M. J. Hayen, S. E. Johnson, and G. E. Dahl. 2011. Effect of heat stress during the dry period on mammary gland development. J. Dairy Sci. 94:5976-5986.

Tao, S., I. M. Thompson, A. P. A. Monteiro, M. J. Hayen, L. J. Young, and G. E. Dahl. 2012. Effect of cooling heat-stressed dairy cows during the dry period on insulin response. J. Dairy Sci. 95:50355046

Thompson, I. M. T., S. Tao, A. P. A. Monteiro, K. C. Jeong, and G. E. Dahl. 2014. Effect of cooling during the dry period on immune response after Streptococcus uberis intramammary infection challenge of dairy cows. J. Dairy Sci. 97:7426-7436.

Vergara, C. F., D. Dopfer, N. B. Cook, K. V. Nordlund, J. A. A. McArt, D. V. Nydam, and G. R. Oetzel. 2014. Risk factors for postpartum problems in dairy cows: Explanatory and predictive modeling. J. Dairy Sci. 97:4127-4140.

Vieira-Neto, A., F. S. Lima, J. E. P. Santos, R. D. Mingoti, G. S. Vasconcellos, C. A. Risco, and K. N. Galvao. 2016. Vulvovaginal laceration as a risk factor for uterine disease in postpartum dairy cows. J. Dairy Sci. 99:4629-4637.

Visinoni, S., N. F. Khalid, C. N. Joannides, A. Shulkes, M. Yim, J. Whitehead, T. Tiganis, B. J. Lamont, J. M. Favaloro, J. Proietto, S. Andrikopoulos, and B. C. Fam. 2012. The role of liver fructose-1,6-bisphosphatase in regulating appetite and adiposity. Diabetes 61:1122-1132.

Weather Underground. 2016. Hague, FL. https://www.wunderground .com/.

Zenobi, M. G., R. Gardinal, J. E. Zuniga, A. L. G. Dias, C. D. Nelson, J. P. Driver, B. A. Barton, J. E. P. Santos, and C. R. Staples, 2018. Effects of supplementation with ruminally protected choline on performance of multiparous Holstein cows did not depend upon prepartum caloric intake. J. Dairy Sci. 101:1088-1110.

Zimbelman, R. B., R. P. Rhoads, M. L. Rhoads, G. C. Duff, L. H. Baumgard, and R. J. Collier. 2009. A re-evaluation of the impact of temperature humidity index (THI) and black globe humidity index (BGHI) on milk production in high producing dairy cows. Pages 113-125 in Proc. Western Dairy Management Conference, Reno, NV. Department of Animal Sciences, University of Arizona. 